evidence approach including in vivo toxicity studies, the overall nature and frequency of the toxicities observed, and the patient population and/or disease indication being considered.

\section{COMPETING FINANCIAL INTERESTS}

The authors declare competing financial interests: details are available at http://www.nature.com/ doifinder/10.1038/nbt.2376.

\begin{tabular}{|c|}
\hline 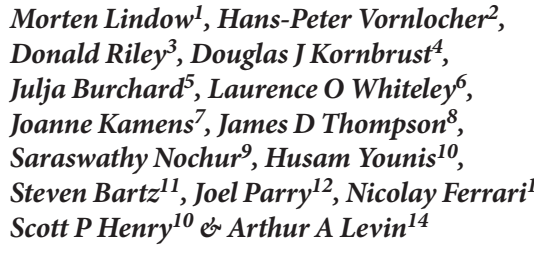 \\
\hline $\begin{array}{l}\text { Position of the Oligonucleotide Safety Working } \\
\text { Group: Off-Target Effects Subcommittee. } \\
\text { 'Santaris Pharma A/S, Hørsholm, Denmark. } \\
{ }^{2} \text { Axolabs GmbH, Kulmbach, Germany. }{ }^{3} \text { DNA } \\
\text { Consulting LLC, Ellensburg, Washington, } \\
\text { USA. }{ }^{4} \text { Preclinsight, Reno, Nevada, USA. } \\
{ }^{5} \text { Merck \& Co., Inc., West Point, Pennsylvania, } \\
\text { USA. }{ }^{6} \text { Pfizer, Cambridge, Massachusetts, } \\
\text { USA. }{ }^{7} \text { RXi, Worcester, Massachusetts, USA. }\end{array}$ \\
\hline
\end{tabular}

Morten Lindow ${ }^{1}$, Hans-Peter Vornlocher ${ }^{2}$, Donald Riley ${ }^{3}$, Douglas J Kornbrust ${ }^{4}$, Julja Burchard ${ }^{5}$, Laurence O Whiteley ${ }^{6}$, Joanne Kamens ${ }^{7}$, James D Thompson ${ }^{8}$ Saraswathy Nochur ${ }^{9}$, Husam Younis ${ }^{10}$, Steven Bart ${ }^{11}$, Joel Parry ${ }^{12}$, Nicolay Ferrari ${ }^{13}$, Scott P Henry 10 \& Arthur A Levin Group: Off-Target Effects Subcommittee. ${ }^{1}$ Santaris Pharma A/S, Hørsholm, Denmark. ${ }^{2}$ Axolabs GmbH, Kulmbach, Germany. ${ }^{3} \mathrm{DNA}$ Consulting LLC, Ellensburg, Washington USA. ${ }^{6}$ Pfizer, Cambridge, Massachusetts,
${ }^{8}$ Quark Pharmaceuticals, Boulder, Colorado, USA. ${ }^{9}$ Alnylam Therapeutics, Cambridge, Massachusetts, USA. ${ }^{10}$ Isis Pharmaceuticals, Carlsbad, California, USA. ${ }^{11}$ Merck \& Co., Inc., Palo Alto, California, USA. ${ }^{12}$ GlaxoSmithKline R\&D, Ware, Hertfordshire, UK. ${ }^{13}$ Topigen Pharmaceuticals, Pharmaxis Ltd., Montreal, Quebec, Canada. ${ }^{14}$ miRagen Therapeutics, Boulder, Colorado, USA.

e-mail:art.levin@miragenrx.com

1. Zamecnik, P.C. \& Stephenson, M.L. Proc. Natl. Acad. Sci. USA 75, 280-284 (1978).

2. Fire, A. et al. Nature $391,806-811$ (1998)

3. Henry, S. et al. Toxicologic properties of 2'-methoxyethyl chimeric antisense inhibitors in animals and man. in Antisense Drug Technology: Principles Strategies, and Applications. (ed. Crooke, S.T.) 327-364 (CRC Press, 2007)

4. Sheehan, J.P. \& Phan, T.M. Biochemistry 40, 49804989 (2001).

5. Bennett, C.F. \& Swayze, E.E. Annu. Rev. Pharmacol. Toxicol. 50, 259-293 (2010).

6. Burchard, J. et al. RNA 15, 308-315 (2009).

7. Jackson, A.L. et al. RNA 12, 1179-1187 (2006).

8. Snøve, O. \& Holen, T. Biochem. Biophys. Res. Commun. 319, 256-263 (2004).

9. Jackson, A.L. et al. Nat. Biotechnol. 21, 635-637 (2003).

10. Schwarz, D.S. et al. PLoS Genet. 2, e140 (2006).

11. Obad, S. et al. Nat. Genet. 43, 371-378 (2011).

\title{
Innovative drugs and vaccines in China, India and Brazil
}

\section{To the Editor:}

After decades of copying existing health products developed elsewhere, a growing number of indigenous enterprises in China, India and Brazil have begun to develop innovative products of their own. This change has been sparked by these countries' adoption of pharmaceutical product patent regimes-as part of their commitments under the World Trade Organization's TradeRelated Aspects of Intellectual Property Rights (TRIPS) agreement-and enhanced governmental support for innovation. During the past 4 years, we have published a series of articles in this journal discussing health biotech sectors in China, India and Brazil $^{1-3}$. Each of those studies focused on indigenous health biotech enterprises and covered products and services, partnerships, intellectual property portfolios, business models, financial environments, entrepreneurial barriers to innovation and recommendations for advancing health biotech innovation in each country. Here, we build upon and update the aforementioned studies by focusing more directly on innovative vaccines and therapeutics in the pipelines of indigenous enterprises in China,
India and Brazil. Specifically, we examine pharmaceutical innovations based on small-molecule drug development involving new chemical entities (NCEs); biotech innovations based on large molecules, nucleic acids, proteins and/or peptides and whole cells (collectively referred to as biotechnological entities); innovations involving traditional medicines, herbal compounds and other biodiversity resources, which we collectively referred to as plantbased medicines; the extent to which the products and/or technologies identified have been in-licensed from foreign sources or out-licensed to them; and how the disease focus of the overall innovation pipelines of Chinese, Indian and Brazilian firms compare with drug and vaccine innovation in the industrialized world, as judged by the US Food and Drug Administration (FDA) approvals over the past 15 years.

Two key criteria were used to select firms in our analysis: first, companies had to be indigenous enterprises when they undertook related innovations and not offshoots of multinational corporations or foreign companies; and second, firms needed to have one or more new vaccine or therapeutic leads in their pipeline and/or have already succeeded in developing and marketing such products. Company selection was informed by our previous studies, through an extensive search of publicly available online sources and publications, and consultations with key informants familiar with biotech and pharmaceutical sectors in each country. Approximately two-thirds of companies included for this analysis have been interviewed as part of our ongoing studies, whereas one-third update that earlier data set. Data derive from interviews with firm representatives (two-thirds of companies), ongoing correspondence with firm representatives, company websites and other publicly available online sources. Information regarding specific product leads, their chemical and/or molecular nature, targeted indication(s), latest known developmental phase, and licensing and/ or partnering status were tabulated and analyzed.

Several limitations and clarifications to our study are noteworthy. First, although considerable attempts have been made to identify all companies and products, limitations on the amount of publicly available information and constraints implicit in English-language web-based enquiries mean that our survey might not have captured all products and companies that fit the selection criteria. Second, time lags associated with conducting the research and publication, as well as those associated with delays by companies in publicizing or disclosing relevant information means that some of the information may not be up to date. Third, judgments regarding the degree of scientific novelty are subject to limitations on publicly available information related to specific products. For the purposes of this article, we have relied on declaration of novelty by firms as well as our own judgment to select products that we believe represent substantial technological advancements and require considerable technical and financial resources to commercialize. Furthermore, in some cases, a given drug candidate, or different formulations of it, is being developed for different indications. In these cases, we have followed company classifications to decide whether they represent one or more unique candidates. Fourth, the results presented here do not include innovative products that have been abandoned and/or failed during development, but are rather focused on products that are actively being pursued. However, in some cases development may be temporarily stalled or slow. Lastly, as 
public research institutions and universities independently engage in some drug and vaccine innovation in each of the countries studied-but have not been included in this analysis-the data presented should not be taken to represent the overall innovative capability of the nations concerned but rather that of the entrepreneurial sector in each country. Notwithstanding the stated limitations, we believe the data presented provide an accurate snapshot of the overall innovative effort by indigenous enterprises in the emerging markets studied.

In total, we identified 165 innovative products within 41 indigenous firms in China, India and Brazil. Data on specific firms, their innovative products, respective development phase and licensing status are presented in Supplementary Tables 1-4 and Figures 1 and 2 . Of all the products studied, Indian firms had 90 (55\% of total), Chinese firms had 48 (29\%) and Brazilian firms had 27 (16\%). Data on how innovations in the firms studied, as a group, compare with historical FDA approvals are displayed in Figure 3 and Supplementary Figures 1 and 2.

Overall, chemistry-based pharmaceuticals represent the majority (53\%) of all innovations identified followed by biotechbased products (at 38\%) and plant-based medicines (9\%). There is considerable variation however in their distribution across countries (Fig. 1). Pharmaceutical innovation in India comprised $65 \%$ of innovative products for this country and $67 \%$ of all pharmaceutical innovations identified across the three countries combined.

This observation is a reflection of India's considerable expertise in chemistry-based pharmaceuticals. In contrast, Chinese firms have a greater focus on biotech innovations (55\% of products for this country). This is due, in part, to the more permissive regulatory environment for leading edge technologies (such as genetic and stem cell therapies) in China as well as considerable support for novel drug discovery and development from governmental sources.

Biotech products by Indian and Brazilian firms account for $28 \%$ and $41 \%$ of their overall innovation focus. Brazil's greater focus on plant-based medicines (18\% of its innovations) distinguishes it from China (at 8\%) and India (at 7\%), although in absolute terms these countries have a roughly equal focus on this area. The composition of innovations in terms of the portion of innovations that rely on chemistry- and biotech-based applications is comparable across the emerging markets and FDA-approved cohort of firms (Fig. 3).

The majority ( $82 \%$ ) of all product leads identified across the three countries target therapeutic applications. This portion is composed of all pharmaceutical, 53\% of biotech and all plant-based product leads identified. Over half (62\%) of biotech-based leads in China are targeted at therapeutic applications compared to $32 \%$ in India-relating to China's unique focus on genetic and stem cell therapies and India's greater focus on vaccines for communicable diseases. Gene therapy products marketed a few years ago by Shanghai Sunway (Shanghai) and Shenzhen SiBiono (Shenzhen) are among ten such products within four Chinese companies. Several Chinese companies, including Beike Biotechnology (Shenzhen) and SinoCells Bio Technologies (Beijing), are engaged in development and marketing of stem cell therapies ${ }^{4}$. Other biotechnological entities in development include peptide-based therapeutic candidates and monoclonal antibodies (mAbs). Biocon's (Bangalore) oral insulin and Zensun's (Shanghai) recombinant peptide against heart failure are in phase 3 clinical development. The most advanced $\mathrm{mAb}$ candidates include one

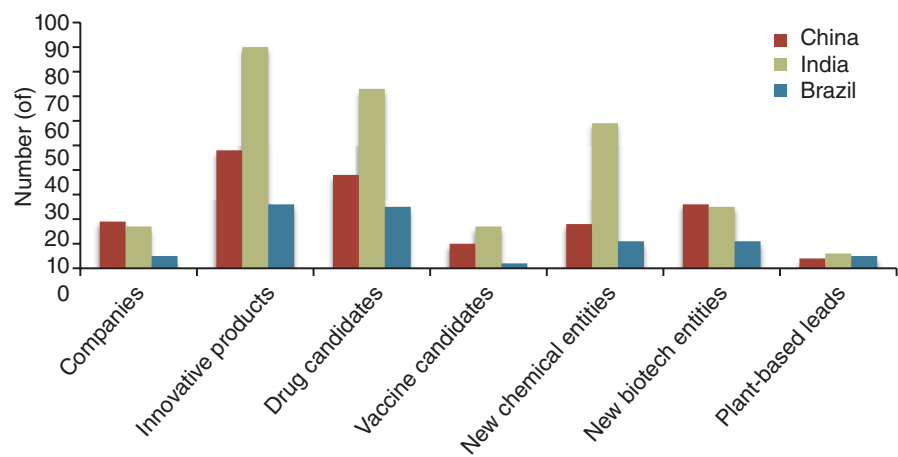

Figure 1 Number of innovative companies and products, drug and vaccine candidates, new chemical entities, new biotech entities and plant-based leads by indigenous companies in China, India and Brazil.

against psoriasis and rheumatoid arthritis being developed by Biocon (phases 3 and 2 , respectively) and another against ovarian cancer by Brazil's Recepta Biopharma based in São Paulo (which is in phase 2 testing).

Approximately $18 \%$ of all products identified in the survey are vaccines. Of the 29 vaccines and/or vaccine candidates identified, India accounts for 17 (59\% of total), followed by China at 10 (34\%) and Brazil at 2 (7\%). Almost all vaccine leads in China and India target infectious diseases. Examples of innovations in this category include the following: marketed H1N1 influenza vaccines from China's SinoVac (Beijing) and India’s Bharat Biotech (Hyderabad), Zydus Cadila (Ahmadabad) and the Serum Institute of India (Pune); a novel hepatitis E vaccine awaiting Chinese regulatory approval by China's Xiamen Innovax Biotech (Xiamen) and Beijing Wantai; and two anti-malaria vaccines in development by Bharat Biotech and Ranbaxy (Gurgaon, India). Brazil's FK Biotec (Porto Alegre) has two therapeutic vaccines in development against prostate cancer (in phase 3 trials) and myeloma (in phase 1 testing), whereas China's Zensun is developing a therapeutic vaccine for ErbB2 overexpressing breast, ovarian, colon, lung and prostate cancers (which is in phase 1 testing). Our findings also suggest that firms in India and China may have a greater focus on vaccine development than those in the industrialized world (Fig. 3).

The majority of innovative products are at an early developmental stage. Overall, $\sim 60 \%$ of innovative products identified are in the preclinical or phase 1 stage (Fig. 2). Thus far, 16 innovative products identified ( $10 \%$ of total) have reached the domestic market, with China and India accounting for seven each. Another 15 (9\% of total) product leads are in phase 3 clinical trials or awaiting regulatory approval from their respective national regulatory agencies, with India accounting for 10 , followed by China and Brazil at 2 and 3, respectively. Balaglitazone, a lead drug candidate for type 2 diabetes discovered by India's Dr. Reddy's Laboratories and being co-developed with Denmark's Rheoscience (Roedovre), had the potential to become the first major FDA-approved innovative drug developed by an emerging market company. However, recent safety concerns regarding other drugs in the PPAR-gamma agonist family have put this prospect in doubt. Other products in phase 3 testing include: a lead candidate for diabetes by Glenmark and partners; 


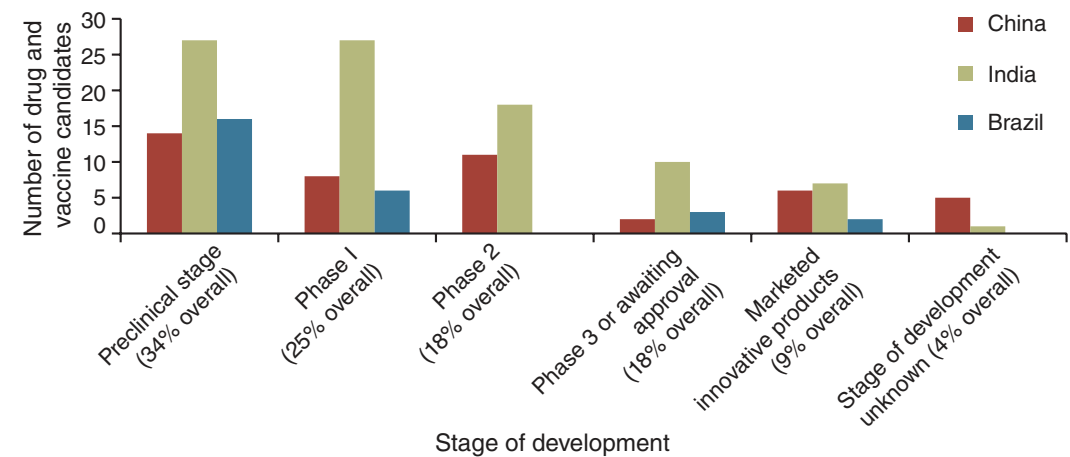

Figure 2 Total number (and percentage) of innovative drug and vaccine candidates within indigenous companies in China, India and Brazil grouped by stage of development.

an oral insulin formulation by Biocon; a recombinant peptide for heart failure and dilated cardiomyopathy by Zensun; and Aché Laboratories' (São Paulo, Brazil) phytotherapeutic against metabolic syndrome.

In comparison to the focus of firms that have had products approved through the FDA over the past 15 years, the companies in all three emerging economies studied here as a group appear similar in their overall disease focus. The leading disease group indications for FDA-approved drugs and vaccines between 1995 and 2011 were infectious disease (18.5\%), oncology (13\%) and cardiovascular disease (7.8\%) (Supplementary Fig. 1). In contrast, leading disease indications for the pipeline of products studied in China, India and Brazil are infectious disease (26.7\%), oncology (25\%) and neurology (13.3\%; Supplementary Fig. 2). Although the top five disease groups represented by the FDAapproved drugs and vaccines comprise $49 \%$ of the total approvals during the stated period, the top 5 disease groups for emerging market firms studied make up $\sim 80 \%$ of the products identified. Therefore, the companies studied as a group appear highly focused on relatively few disease areas.

Notwithstanding the stated observations, the results also reveal considerable heterogeneity across individual countries regarding targeted disease areas. For example, India accounts for about $66 \%$ of all products in the three countries that target infectious diseases, whereas China accounts for $57 \%$ of all products for oncology. Similarly, India also contributes $85 \%$ of innovations targeted at diabetes, making this disease among the top five diseases targeted by all companies studied in that country. The leading disease group for Brazilian firms was oncology with no obvious preference in other areas.
Approximately 16 (10\%) of all innovations in the three countries target diseases that almost exclusively affect the developing world - with all but two being vaccines. Examples of such products include: cholera vaccines (by India's Shantha Biotechnics and China's Shanghai United Cell Biotechnology), three rotavirus vaccine candidates in phase 2/3 testing (by Shantha Biotech, the Serum Institute and Bharat Biotech), an anti-malaria vaccine (by Bharat Biotech), an anti-malarial drug by Ranbaxy and a drug candidate for tuberculosis by Lupin Pharmaceuticals (Pune).

The vast majority (90\%) of innovations by emerging market firms target global diseases that have markets in both developed and developing nations. The leading indications targeted by the Chinese and Brazilian firms studied involve various forms of cancer, accounting for approximately half and one-third of innovative products in these countries, respectively. In contrast, the most commonly targeted indications by Indian companies involve diabetes and related conditions ( $21 \%$ of their products), followed by cancer $(10 \%)$. Liver disease prevention and treatment constitutes the second most based on nature of active substance. commonly targeted indication among the Chinese firms studied-accounting for $\sim 17 \%$ of their products. Furthermore, among the innovative leads in China that target cancer there is a considerable emphasis on head and neck cancers. Previous studies have shown that liver diseases and head and neck cancers are of particular relevance to China ${ }^{5-9}$ and diabetes is a major and growing condition afflicting the Indian population ${ }^{10,11}$.

Our findings suggest that in-licensing of lead drug and vaccine candidates from foreign entities has thus far been a relatively infrequent occurrence across the countries studied. Through an online search of publicly accessible information, as well as data gleaned from company websites and interview data, we found that almost all of the innovative products identified within the Chinese and Brazilian companies and $\sim 83 \%$ of products within Indian enterprises were either developed and/or discovered by the firms themselves or originate from domestic universities and research institutes. Approximately $17 \%$ of innovative products in India rely on technological in-licensing from abroad (Supplementary Table 4), whereas Indian companies have also been engaged in out-licensing some of their pipeline products ( $~ 8 \%$ of the products identified). India's relatively enhanced level of collaboration with foreign firms is likely driven by a host of factors including: common use of the English language, the historically export-orientated nature of the Indian pharmaceutical and biotech industries, and an early foray into NCE discovery by leading Indian firms such as Glenmark, Dr. Reddy's and Ranbaxy.

Notwithstanding the above observations, it is likely that our data underestimate the true extent of in-, and/or out-licensing by the companies studied, owing to limitations on freely available information online.

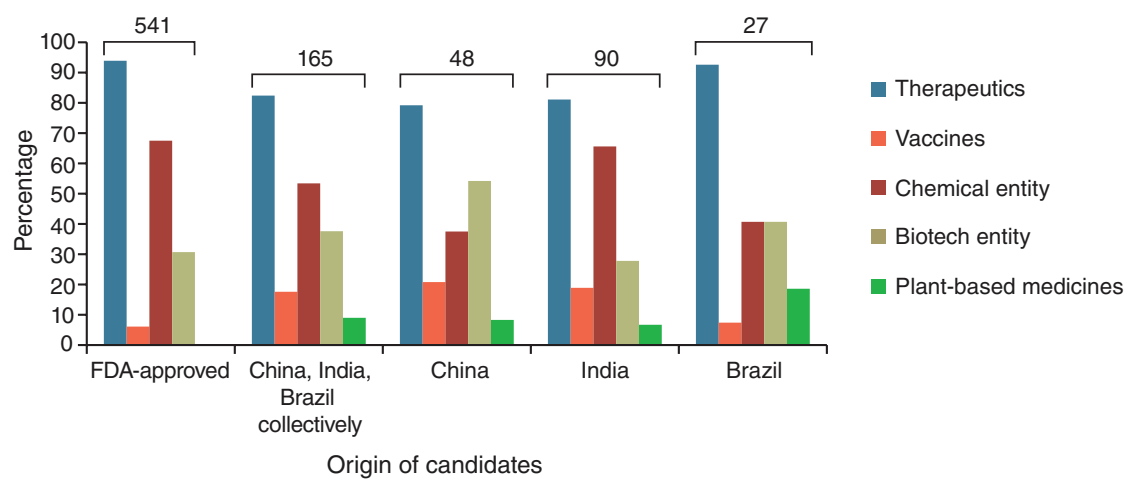

Figure 3 Comparison of FDA-approved drug and vaccine candidates (1995 to April 2011) compared with the innovation pipelines of domestic firms from China, India and Brazil and product breakdown 
Nonetheless, the highly skewed nature of our findings suggests that the products listed in this paper appear to predominantly originate from domestic sources, thus reflecting domestic innovative capability; however, during their course of development, they often borrow from platform and other technologies developed elsewhere. This phenomenon is of course not unique to companies in the emerging markets.

Although limited in scope, licensing arrangements often form the basis for collaborative product development and do play a key role in the innovation strategy of select firms in a number of ways. For instance, China's Shenzhen Chipscreen's and HUYA Bioscience International (San Diego) collaborate on development of the former's anti-cancer product chitamide. Another example involved nimotuzumab, which is an anti-cancer IgG1 humanized $\mathrm{mAb}$ that was originally discovered by Cuba's Centre of Molecular Immunology but subsequently commercialized in India through a joint venture between this institution and Biocon. In other cases, assigning future marketing and development rights to foreign firms facilitates project financing vis-à-vis upfront and milestone payments to inventors. For example, although Glenmark's TRPV3 (transient receptor potential vanilloid) antagonist product for pain and skin disorders was outlicensed to Sanofi (formerly Sanofi-Aventis; Paris), Glenmark continues to develop it with upfront and milestone payments from Sanofi in return for future marketing rights in certain countries. Other arrangements relate to financing of innovative activities within Indian firms by pharmaceutical multinational corporations in return for future discoveries of lead products. In this category, Zydus Cadila, Piramal Life Sciences and Torrent Pharmaceuticals (Ahmedabad) have agreements with Eli Lilly (Indianapolis), Merck and AstraZeneca (London) to develop lead products for cardiovascular, oncology and hypertension, respectively. Similarly, China's Hutchison Medipharma has drug discovery and development agreements with Eli Lilly, Merck KGaA (Armstadt, Germany), Procter \& Gamble (Cincinnati) and OrthoMcNeil-Janssen Pharmaceuticals (Raritan, NJ, USA).

To our knowledge, this is the first empirical study to detail innovative health products in the pipeline of companies in these emerging economies in a comprehensive fashion. The results presented here suggest that the near monopoly on innovation in vaccines and medicines by firms in the industrialized world is near an end. "India is poised to become the medicine maker to the world," Swati Piramal, vice chairperson of Piramal Life Sciences (Mumbai) told us in an interview. Similarly, Samantha Du, the then CEO of the Shanghai-based Hutchison Medipharma, told us that Hutchison's business model is to innovate in China for the global market. The confidence exuded by Piramal and Du is increasingly common among other health entrepreneurs across the emerging markets that we have encountered over the past 5 years.

Clearly, our survey cannot identify every innovative product or every innovating company in China, India and Brazil, so the view presented here is necessarily incomplete. However, it is apparent that a growing number of health enterprises in these emerging economies are moving up the value chain by taking on the more challenging and costly innovations required to create new and improved medicines and vaccines. At the same time, most of the innovative products that we have identified remain in the early stages of development. So the full force of the innovative capability of these countries will be seen in the future. The growing interconnectedness of innovative activities across firms and other institutions in different countries will increasingly make it difficult to ascribe given innovations to specific nations.

Although largely focused on global diseases, the Chinese and Indian firms studied exhibit a predilection for the subset of global diseases that are most relevant to their domestic populations. This relates, in part, to the relative ease of obtaining domestic regulatory approval with subsequent global marketing, but the firms studied appear to be using the power of the global market to advance innovations that can especially benefit local patients. Therefore, the growing innovative capability of domestic companies in China and India may serve to preferentially address locally relevant and increasingly burdensome diseases (including noncommunicable diseases that are a rising burden on healthcare systems in developing countries $^{12}$ ).

We predict that the globalization of health product innovation will have a major effect not only on developing world health systems but also health systems in the developed world, especially as the latter systems struggle with escalating costs. As innovative products move through the pipeline in these countries, the shift in global health product innovation will become more and more apparent.

Note: Supplementary information is available at http:// www.nature.com/doifinder/10.1038/nbt.2380.

\section{ACKNOWLEDGMENTS}

We gratefully acknowledge the comments of J. Clark. We are indebted to the numerous interviewees in Brazil, China and India for sharing their time, experiences and insights with us. This research was funded by Genome Canada through the Ontario Genomics Institute (Toronto), the Ontario Research Fund (Toronto), Rockefeller Foundation (New York) and BioVentures for Global Health (Washington, DC, USA). R.R. was supported by a Doctoral Research Award from the Canadian Institutes of Health Research, and a post-doctoral research fellowship from the University of Toronto's Rotman School of Management and Munk School of Global Affairs, and the Asia Pacific Foundation of Canada (Vancouver). This research was based at the Sandra Rotman Centre (S.R.C.), the University of Toronto and the University Health Network (Toronto). The S.R.C. is financially supported from a variety of sources (http://www. srcglobal.org/).

\section{COMPETING FINANCIAL INTERESTS}

The authors declare competing financial interests: details accompany the full-text HTML version of the paper at http://www.nature.com/ naturebiotechnology/.

Rahim Rezaie ${ }^{1,2}$, Anita M McGahan ${ }^{1}$, Abdallah S Daar ${ }^{3,4}$ \& Peter A Singer ${ }^{1}$

${ }^{1}$ Rotman School of Management and Munk School of Global Affairs, University of Toronto, Toronto, Ontario, Canada. ${ }^{2}$ Asia Pacific Foundation of Canada, Vancouver, British Columbia, Canada. ${ }^{3}$ Sandra Rotman Centre, University Health Network and University of Toronto, Toronto, Ontario, Canada. ${ }^{4}$ Grand Challenges Canada, Toronto, Ontario, Canada. e-mail:peter.singer@srcglobal.org

1. Frew, S.E. et al. Nat. Biotechnol. 26, 37-53 (2008)

2. Frew, S.E. et al. Nat. Biotechnol. 25, 403-417 (2007).

3. Rezaie, R. et al. Nat. Biotechnol. 26, 627-644 (2008).

4. McMahon, D.S., Thorsteinsdóttir, H., Singer, P.A. \& Daar, A.S. Regen. Med. 5, 35-44 (2010).

5. Liang, X. et al. Vaccine 27, 6550-6557 (2009).

6. Perz, J., Armstrong, G.L., Farrington, L.A., Hutin, Y.J.F. \& Bell, B.P. J. Hepatol. 45, 529-538 (2006).

7. He, J. et al. N. Engl. J. Med. 353, 1124-1134 (2005).

8. Yu, M. \& Yuan, J. Semin. Cancer Biol. 12, 421-429 (2002).

9. Jia, W. et al. BMC Cancer 6, 178 (2006).

10. Ramachandran, A. et al. Diabetologia 44, 1094-1101 (2001).

11. Shaw, J.E., Sicree, R.A., Zimmet, P.Z. Diabetes Res. Clin. Pr. 87, 4-14 (2010).

12. Daar, A.S. et al. Nature 450, 494-496 (2007). 